\title{
FATE OF WILD-CAUGHT ANTECHINUS FLAVIPES RELEASED AFTER PHYSIOLOGICAL EXPERIMENTS
}

\author{
C.E. Cooper ${ }^{1}$, K. Vernes $^{2}$, and T. Cooper ${ }^{2}$ \\ ${ }^{1}$ Centre of Ecosystem Diversity and Dynamics in the Department of Environmental \\ and Aquatic Sciences, Curtin University of Technology, PO Box U1987 Bentley \\ Western Australia 6845 \\ ${ }^{2}$ Ecosystem Management, University of New England, Armidale, New South Wales \\ 2351
}

\begin{abstract}
Animals may be released into the wild for introduction, translocation or rehabilitation programs. Often, released animals do not survive or reproduce as well as wild conspecifics. Another circumstance whereby animals may be released is the return to the wild of research subjects, and although these animals may be expected to fare better than those from introduction, translocation or rehabilitation programs, there is little information regarding their subsequent survival and reproduction. We examine here the survivorship and reproductive success of five (one male, four female) yellowfooted antechinus (Antechinus flavipes) released back into the wild after being held in captivity for approximately one week for physiological experiments. Three of the four female Antechinus were recaptured after release, and on inspection, all three had ten pouch young. Survivorship after release of antechinus held in captivity (0.75) was not different for the population as a whole, which ranged between 0.5 and 1.0. We therefore present unequivocal evidence that Antechinus released into the wild after physiological experiments can successfully survive and reproduce. This information is important for wildlife managers and animal ethics committees when considering the fate of ex-research animals.
\end{abstract}


Many studies have examined the fate of animals released into the wild (see review by Fischer and Lindenmayer 2000). Such releases are usually carried out to introduce captive-bred individuals into areas deemed as suitable habitat, to translocate wildcaught individuals into other areas of appropriate habitat, or to release rehabilitated animals after a period of care. Such releases are controversial (Tribe 2002), with some authors arguing that potential adverse effects on the long-term survivorship and/or reproductive success of released individuals mean that it is difficult to justify the practise ethically, ecologically and economically (Estes 1991, 1998). Others argue that release of animals into the wild can be a useful conservation tool, and has an important educational and social function (Klieman 1989; Tribe 2002). Decisions as to whether or not to release animals into the wild are confounded by conflicting results of studies monitoring the long-term survival and/or reproduction of released individuals. Some studies found that the long-term survivorship and/or reproductive output of released animals did not differ from those of their free-living wild conspecifics (e.g. koalas, Phascolarctos cinereus, Lunney et al. 2004; harbour seals, Phoca vitulina, Lander et al. 2002; ringtail possums, Pseudocheirus peregrinus, Augee et al. 1996). Other studies found that released individuals fared significantly worse than their free-living counterparts (e.g. Golden lion tamarins, Leontopithecus rosalia, Beck et al. 1991; European otters, Lutra lutra, Sjöasen 1996; little penguins, Eudyptula minor, Giese et al. 2000; Goldsworthy et al. 2000). However, many studies did not compare the fate of released animals with those of free-living wild individuals, making it difficult to interpret survivorship and reproductive data (Lunney et al. 2004; e.g. blackfooted ferrets Mustela nigripes, Biggins et al. 1999; African penguins Spheniscus demersus, Underhill et al. 1999). Such disparate results make it difficult for wildlife managers and animal ethics committees to make sound and consistent judgments about the release of animals into the wild.

Another circumstance under which animals are released into the wild is the return of animals used for scientific experiments. Here healthy individuals are wildcaught and maintained in captivity for a period of time to undergo various studies under controlled conditions (e.g. measurement of standard physiological variables such as basal metabolic rate, evaporative water loss, ventilatory parameters, torpor use etc). At the conclusion of these experiments, animals may be returned to the wild at the point of capture (with alternatives including euthanasia, donation to zoos, wildlife parks or museums, or maintenance of the animal in captivity until it dies of natural 
causes). However, we are not aware of any studies that examine the survivorship of individuals released after involvement in such research activities.

We captured seven (one male and six females) yellow-footed antechinus (Antechinus flavipes) in aluminium box traps at the University of New England's Newholme Field Laboratory $\left(30^{\circ} \mathrm{C} 23^{\prime} \mathrm{S} 151^{\circ} \mathrm{C} 38^{\prime} \mathrm{E}\right), 10 \mathrm{~km}$ north of Armidale, N.S.W., during July 2007, for physiological experiments. Five individuals (one male, four females) were captured on two 1-ha grids which formed part of an on-going ecological study, while two females were from other sites at Newholme which were not subsequently monitored. The A. flavipes were transported to a laboratory at the University of New England where they were housed indoors in large plastic crates, at an ambient temperature of $\sim 20^{\circ} \mathrm{C}$ under natural photoperiod, for approximately one week. Animals were fed with tinned cat food and mince meat, with ad libitum water, and were provided with a wood shaving substrate, and cardboard boxes with shredded paper for shelter. During this period, their metabolic rate, evaporative water loss and ventilatory parameters were measured at a thermoneutral $\mathrm{T}_{\mathrm{a}}$ of $30^{\circ} \mathrm{C}$ using noninvasive standard flow-through respirometry and plethysmography (see Withers 2001 and Cooper et al. 2009 for a general description of the methods). At the conclusion of the study, each individual was released back into the wild at their point of capture. Five of the antechinus used in this physiological study (one male, four females) had been captured and individually marked (ear notched) previously during an on-going ecological study (monthly trapping at two 1-ha grids for three consecutive nights from August 2006 to July 2007, 150 trap nights per month), and subsequent trapping of the same area after the physiological experiments (three nights/150 trap nights at the same grids in each of September and October 2007) enabled us to examine the survivorship of these individuals, and directly compare this with the individuals trapped but not held in captivity. However, because survivorship cannot be calculated for the last two trapping periods of a mark-recapture study (see Krebs 1999), probability of survivorship could only be calculated up to July 2007.

The male A. flavipes was not captured during subsequent trapping (which occurred after the conclusion of the breeding season) as expected due to welldocumented dispersal and post-reproductive male die-off in this species (for a review see Tyndale-Biscoe, 2005). None of the other seven males captured previously during 2007 were captured again during September or October. Of the seven females captured on the trapping girds in July, three were recaptured, all which were 
individuals held in captivity for physiological experiments. None of the three females which were trapped but not held in captivity were re-trapped. All three captive-held females were later found to each have 10 pouch young during the post-release trapping in late September, indicating that not only did they survive in the wild after release, but that they also reproduced. Calculation of the probability of monthly survival using the Jolly-Seber routine in Krebs (1999) indicated that probability of survival for female $A$. flavipes at our study site fluctuated between 0.5 and 1.0 (mean $=0.87$ ) over a 12-month period (August $2007-$ July 2008; $\mathrm{N}$ individuals $=12$ ), with the lowest survivorship (0.5) calculated during the post-mating period in July, when females were rearing young. July 2008 probability of survivorship for the female animals held in captivity ( $\mathrm{N}$ individuals $=4$ ) and subsequently released and monitored was 0.75 , falling within the range recorded for the population during the previous year. In the very least, being held in captivity did not diminish the probability of antechinus surviving to breed in the wild once released, and it is possible that access to ad libitum food, protection from predators, and provision of shelter and a stable microclimate in captivity may have even increased their fitness relative to those not removed from the wild. Captivity has been shown to increased the survivorship of other mammal species; Molony et al. (2006) demonstrated that translocation of hedgehogs (Erinaceus europaeus) increased their probability of survivorship, and this was believed to be related to a build up of fat reserves and reduced stress from contact with humans in the captive individuals.

It is our experience that ethics committees, environmental licensing agencies and other researchers cite evidence of the poor survivorship of many animals undergoing introduction/translocation/rehabilitation release as reasons not to rerelease research subjects at the conclusion of experiments. However, the circumstances of the capture and release of ex-research animals differ substantially from other types of release programs. Experimental animals are usually healthy adult individuals when taken from the wild, and are released directly at their point of capture after a period of time in captivity under optimal conditions of diet and housing. This differs dramatically from captive-bred individuals introduced to new habitats in introduction programs, wild-caught individuals translocated to new areas, or rehabilitated injured, ill or orphaned animals re-released into the wild at either their original or a new location. Familiarity with the release environment has been shown to have a substantial effect on release success (e.g. Augee et al. 1996) with release 
programs more successful if animals are returned to their original location (Fischer and Lindenmayer 2000; Lunney et al. 2004). Survival of wild-born individuals is higher than for those bred in captivity (Fischer and Lindenmayer 2000; Jule et al. 2008) and experience with survival skills such as predator avoidance or foraging improves survivorship (Biggins et al. 1999; Stoinski et al. 2003; Shier and Owings 2006). For rehabilitated animals, the extent of the original trauma, body mass and condition may affect release success (Goldsworthy et al. 2000). Therefore, it may be expected that the post-release survival of animals held temporarily in captivity for scientific purposes will be greater than predicted for introduction/translocation/rehabilitation programs. It is possible that the nature of the experimental procedures carried out during captivity may influence post-release survival. The experiments conducted during this study were non-invasive, but presumably the animals did undergo some degree of stress associated with contact with humans and handling, an unfamiliar environment and novel food. However, there is no evidence that this presumed stress had any negative impact on the postrelease survival and reproduction of A. flavipes.

We appreciate that our recapture data is based on a small sample size, and therefore the data must be interpreted with caution. Generally only the minimal number of individuals required for statistical significance of physiological data (usually $\mathrm{N}=6-8$ ) are captured from the wild for ethical, conservation and economic reasons, and therefore large sample sizes required to statistically test differences in survivorship as seen in studies of released/translocated/rehabilitated animals are unlikely. The resources to monitor the fate of released research animals are also seldom available, as time and funding are tied to the actual experimental outcomes, and animals for physiological studies are usually deliberately sourced from areas other than those where monitoring or ongoing ecological studies occur, to avoid disrupting the results of these other research programs. This limits the opportunity to undertake research into the fate of released research animals. In this respect our study is unique, and although the dataset is limited, the survival and reproductive success of three released A. flavipes provides unequivocal evidence that individuals held in captivity for physiological experiments can be successfully released back into the wild. Further studies into the success of release of research animals into the wild are highly desirable. 


\section{ACKNOWLEDGEMENTS}

Physiological studies were carried out in collaboration with Professor Philip Withers and Professor Fritz Geiser, and we thank them for their ideas and comments on the manuscript. The trapping study of Antechinus at Newholme was funded by an ARC Discovery Grant (DP0557022) to KV, and the physiological experiments by an ARC Discovery Grant (DP0665044) to CEC. This manuscript is contribution CEDD562009 of the Centre for Ecosystem Diversity and Dynamics, Curtin University. 


\section{REFERENCES}

Augee, ML, Smith B, Rose S, 1996. Survival of wild and handreared ringtail possums (Pseudocheirus peregrinus) in bushland near Sydney. Wildlife Research 23: 99-108.

Beck BB, Kleiman DG, Dietz JM, Castro i, Carvalho C, Martins A and RETTBERG-BECK B, 1991. Losses and reproduction in reintroduced golden lion tamarins Leontopithecus rosalia. Dodo, Journal of the Jersey Wildlife Preservation Trust 27: 50-61.

Biggins DE, VARGAS A, GODBEy JL AND ANDERSON SH, 1999. Influence of prerelease experience on reintroduced black-footed ferrets (Mustela nigripes). Biological Conservation 89:121-129

COOPER CE, Withers PC, AND CRUZ-Neto AP, 2009. Metabolic, ventilatory and hygric physiology of the gracile mouse opossum (Gracilinanus agilis). Physiological and Biochemical Zoology 82: 153-162

EsTes JA, 1991. Catastrophes and conservation: lessons from sea otters and the Exxon Valdez. Science 254: 1596

ESTES JA, 1998 Concerns about rehabilitation of oiled wildlife. Conservation Biology 12: $1156-1157$.

FISCHER J AND LINDENMAYER DB, 2000. An assessment of the published results of animal relocations. Biological Conservation 96: 1-1

Giese M, Goldsworthy SD, Gales R, Brothers N, HAMiLl J, 2000. Effects of the Iron Baron oil spill on little penguins (Eudyptula minor). III. Breeding success of rehabilitated oiled birds. Wildlife Research 27: 583-591.

Goldsworthy SD, GIESE M, GALES RP, Brothers N, HAMILl J, 2000. Effects of the Iron Baron oil spill on little penguins (Eudyptula minor). II. Post-release survival of rehabilitated oiled birds. Wildlife Research 27:573-582.

Jule KR, LEAVER LA, LEA SEG, 2008. The effects of captive experience on reintroduction survival in carnivores: A review and analysis. Biological Conservation 141: 355-363

KLIEMAN DG, 1989. Reintroduction of captive mammals for conservation BioScience 39: $152-161$.

KREBS, CJ (1999). Ecological Methodology. Second edition. Addison-Welsey Educational Publishers, Inc. Menlo Park, California. 
LANDER ME, Harvey JT, Hanni KD, Morgan, LE, 2002. Behavior, movements and apparent survival of rehabilitated and free-ranging harbor seal pups. Journal of Wildlife Management 66: 19-28.

Lunney D, Gresser SM, Mahon PS AND MATthews A 2004. Post-fire survival and reproduction of rehabilitated and unburnt koalas. Biological Conservation 120: $567-575$

Molony SE, Dowding CV, BaKer PJ, Cuthill IC AND Harris S, 2006. The effect of translocation and temporary captivity on wildlife rehabilitation success: An experimental study using European hedgehogs (Erinaceus europaeus). Biological Conservation 130: 530-537

SHIER DM, AND OWINGS DH, 2007. Effects of social learning on predator training and postrelease survival in juvenile black-tailed prairie dogs, Cynomys ludovicianus. Animal Behaviour 73: 567-577

SJÖASEN T 1996. Survivorship of captive-bred and wild-caught reintroduced European otters Lutra lutra in Sweden. Biological Conservation 76: 161-165.

Stoinski BB, Beck MA, Bloomsmith TL And MAPle A, 2003. Behavioral comparison of captive-born, reintroduced golden lion tamarins and their wild born offspring Behaviour 140: 137-160.

Tyndale-BIscoe, H. (2005). Life of Marsupials. CSIRO Publishing, Collingwood.

TRIBE A, 2002. Wildlife care and rehabilitation - what can we learn? Rehabilitation and Release 1: 4-5.

Underhill LG, Bartlett PA, BAumann L, Crawford RJM, Dyer BM, Gildenhuys A, Nel DC, OAtley TB, Thornton M, Upfold L, Williams AJ, Whittington PA, WolfaArdt AC, 1999. Mortality and survival of African Penguins Spheniscus demersus involved in the Apollo Sea oil spill: an evaluation of rehabilitation efforts. Ibis 141: 29-37.

WiTHERS PC, 2001. Design, calibration and calculation for flow-through respirometry systems. Australian Journal of Zoology 49: 445-461. 